\title{
A representação social de formação continuada de professores de Educação Física da rede estadual do Espírito Santo
}

\author{
CDD. 20.ed. 371.12 \\ 796.017 \\ http://dx.doi.org/10.1590/1807-55092015000400571
}

\author{
Walk LOUREIRO* \\ Francisco Eduardo CAPARROZ* \\ Valter BRACHT ${ }^{*}$ \\ *Centro de Educação \\ Física e Desportos, \\ Universidade Federal \\ do Espírito Santo.
}

\section{Resumo}

A principal intenção deste texto é apresentar os resultados iniciais de uma investigação que buscou compreender a representação social dos professores de Educação Física da Rede Estadual do Espírito Santo em relação a sua formação continuada. Para tanto escolhe a grande teoria das Representações Sociais, especialmente devido à importância que ela atribui ao senso comum, que é uma das noções centrais para o conceito de representação social. Optando pela Abordagem Estrutural, que corresponde a uma das três correntes que compõem aquela teoria, levanta hipóteses sobre a representação social de formação continuada, tratando de sua organização interna e da dimensão cognitiva da mesma. Aponta para a ocorrência de um fenômeno atual que tem deslocado o núcleo central da representação social de formação continuada da aprendizagem para a qualificação tornando a busca por qualificação na formação continuada um atributo individual, de responsabilidade única e exclusiva do professor.

PalAVRAS-CHAVE: Representações sociais; Núcleo central; Abordagem estrutural; Senso comum.

\section{Introdução}

Temos acompanhado na última década um grande número de açóes governamentais em prol da formação continuada (FC) de professores da Educação Básica e um maior número de estudos desenvolvidos a partir dessa temática ${ }^{1-6}$.

Entretanto, apesar de toda a importância atribuída à $\mathrm{FC}$ na vida profissional de um professor e do aumento de açôes voltadas para a mesma, é possível constatar em um estudo realizado com professores de Educação Física (EF) da Rede Municipal de Vitória, capital do Estado do Espírito Santo ${ }^{7}$, que boa parte dos professores investigados percebiam alguns aspectos negativos nas FC oficiais ${ }^{\mathrm{a}}$ que lhes eram oferecidas, apontando inclusive para a necessidade de superá-los.

\section{Método $^{c}$}

\section{Por que as representações sociais de formação continuada?}

Diante do contexto apresentado anteriormente a escolha pela TRS, foi feita por entendermos que
Esse artigo tem por objetivo apresentar os resultados iniciais de uma investigação que buscou compreender a representação social dos professores de Educação Física da Rede Estadual do Espírito Santo em relação a sua formação continuada. Para tanto apresentamos parte dos resultados de uma pesquisa que realizamos com professores de EF da Rede Estadual pública do Espírito Santo. O artigo está constituído de uma justificativa pela eleiçáo da Teoria das Representaçóes Sociais (TRS) ${ }^{\mathrm{b}}$ e da rede de ensino investigada; das escolhas metodológicas realizadas; do tratamento dos dados obtidos; da análise da representação social de formaçấo continuada propriamente dita; e de nossas conclusões a partir do recorte escolhido.
[...] o conhecimento das representaçôes sociais do professor - como um conjunto organizado de julgamentos, atitudes e informaçóes elaborados a respeito de um objeto social com o objetivo de orientar e justificar práticas - assume relevância 
para orientar políticas voltadas para a formação inicial e continuada do professor $^{8}$ (p.581).

Outra questão que contribuiu para essa escolha foi o fato da teoria em questão atribuir importância ao senso comum sem ter a pretensão de transformar uma representação social em verdade científica, o que reduziria a realidade às concepçóes que o grupo ou sociedade investigados tivessem do objeto estudado ${ }^{9, \mathrm{~d}}$. Compreendemos também que a representação social é uma entre várias outras construçóes mentais originárias do senso comum (tais como a atitude, a ideologia, as imagens sociais, entre outras) e, justamente por isso, afirmamos que o senso comum é um conceito-chave para compreender as representaçóes sociais ${ }^{10}$.

Em suma, optando pela TRS sabíamos que estávamos partindo do ponto de vista do grupo estudado para tentar melhor compreender o fenômeno da formação continuada.

\section{Diferentes abordagens na TRS}

Escolhida a teoria era necessário optar por uma das três "correntes" que compóem essa teoria: a abordagem processual ou "culturalista", a abordagem societal ou escola de Genebra e a abordagem estrutural também conhecida como teoria do Núcleo Central.

Como nosso objetivo era obter um recorte da realidade para, se necessário, propor mudanças qualitativas nas políticas públicas de FC destinadas aos professores de EF, optamos pela abordagem estrutural por dois motivos: pelo desafio e pela possibilidade de realizar uma boa pesquisa quali-quantitativa e o (pouco) tempo disponível para a realização da pesquisa. Afinal, a investigação em questão correspondia a um dos requisitos necessários para a obtenção de titulação de mestre e tanto a abordagem processual, quanto a abordagem societal demandariam um contato de tempo mais prolongado com os sujeitos estudados do que os dois anos dos quais dispúnhamos.

\section{Itinerário metodológico}

Para realização de nossa pesquisa escolhemos a Rede (pública) Estadual. Iniciamos a pesquisa de campo no "II Fórum de Educação Física e Esporte na Escola" na cidade de Guarapari, em dezembro de 2008. Havia a previsão de que 318 dos 761 professores que lecionavam as aulas de EF durante o ano letivo de 2008 para a Secretaria de Estado da Educação (SEDU) participariam do evento.

Sabendo que não existe um modelo, um padrão metodológico a ser seguido nas pesquisas que se valem da TRS ${ }^{11}$, escolhemos dois métodos que poderiam nos ajudar a cercar um fenômeno complexo como a FC ${ }^{12}$ : o Teste de Livre Evocação de Palavras combinado com a técnica do Poder de Associação de Uma Evocação, que explicaremos posteriormente.

O objetivo dessa combinação é tentar descobrir quais os elementos que compóem o núcleo central do objeto estudado elaborando hipóteses para sua organização e para as relaçôes estabelecidas entre eles, de maneira semelhante ao trabalho realizado anteriormente por outros investigadores ${ }^{13-18}$.

A Técnica de Livre Associação consiste em apresentar um termo indutor que represente o objeto de estudo aos sujeitos investigados. Esses indivíduos, por sua vez, designam os elementos que compóem sua representação social em relação àquele objeto, a partir das palavras ou frases que lhes ocorrerem na mente ${ }^{19-20}$. Posteriormente os elementos obtidos são tratados em "software" formado por um grupo de programas desenvolvidos por VERGÈs ${ }^{21}$ denominado EVOC 2000.

Essa técnica apresenta a vantagem de identificar os conteúdos simbólicos das representações sociais ${ }^{15}$ de uma maneira mais espontânea ${ }^{19}$ evitando que aconteça qualquer tipo de filtragem por censura de suas evocaçóes ${ }^{17}$, como acontece no caso da distribuição de questionários estruturados ou semi estruturados.

Já o Poder de Associação de Uma Evocação (que será explicado quando tratarmos os dados da pesquisa de campo) é um recurso bastante usado na busca pela validação dos elementos que aparentemente compóem o núcleo central de uma representação social.

Distribuímos nosso instrumento de coleta de dados para os 250 professores que compareceram ao "II Fórum de Educação Física e Esporte na Escola”. Além de preencher alguns dados solicitados no cabeçalho esses docentes eram convidados a responder nosso teste motivados pela seguinte frase indutora: "Quando ouço falar em formação continuada, penso em...".

Os formulários dos testes dispunham de cinco campos que poderiam ser preenchidos por cada sujeito que se dispusesse participar voluntariamente do estudo, assinalando as palavras e/ou expressóes que lhes conviessem.

\section{Caracterização da amostra}

Apenas 104 dos 250 docentes que participaram do Fórum devolveram os testes preenchidos. Destes um foi descartado porque o informante preencheu-o equivocadamente. Considerando os 761 professores de EF que deram aula na Rede Estadual no ano 
letivo de 2008, obtivemos um recorte bem representativo de toda Rede totalizando $13,5 \%$ com os 103 testes que obtivemos. Na TABELA 1 apresentamos os dados recolhidos mediante o preenchimento do cabeçalho do instrumento distribuído aos educadores participantes do Fórum.

TABELA 1 - Dados relativos à situação funcional dos professores participantes do II Fórum de Educação Física e Esporte na Escola.

\begin{tabular}{cccccccccc}
\hline \multicolumn{2}{c}{ Sexo } & \multicolumn{3}{c}{ Situaçáo funcional } & \multicolumn{3}{c}{ Sindicalizado } & \multicolumn{3}{c}{ Formado em EF } \\
M & F & Efetivo & Contrato temporário & Náo respondeu (NR) & Sim & Náo & NR & Sim & Náo \\
\hline 59 & 45 & 32 & 71 & 1 & 30 & 70 & 4 & 103 & 1 \\
\hline
\end{tabular}

Como é possível notar $59(56,7 \%)$ dos 104 colaboradores são homens e 45 (43,3\%), mulheres; apenas $32(30,8 \%)$ são efetivos contra $71(68,3 \%)$ contratados, enquanto um $(0,9 \%)$ não respondeu. No que se refere à sindicalização, apenas 30 (28,8\%) são filiados ao Sindicato dos Trabalhadores em Educação Pública do Estado do Espírito Santo (SINDIUPES) contra $70(67,3 \%)$ náo filiados; quatro $(3,9 \%)$ não responderam essa questão. Apenas um $(1,0 \%)$ deles não é formado em EF, enquanto 103 (99\%) possuem curso superior nessa área.

Surpreendeu-nos o fato de que $68,3 \%$ dos colaboradores da pesquisa eram docentes em Designação Temporária (DT) ${ }^{\mathrm{f}}$, isto é, com contrato de trabalho por tempo determinado. Ficamos ainda mais surpresos quando recebemos alguns dados que requeremos da SEDU que apontavam que 588 ou $77,3 \%$ de um total de 761 professores de EF, prestaram serviço para essa rede no ano letivo de 2008 no regime de DT.

\section{Tratamento dos dados no EVOC 2000}

A partir do tratamento dos dados fornecidos pelos 103 Testes de Livre Evocação de Palavras considerados válidos chegamos a um total de 146 diferentes categorias de evocaçóes ou palavras evocadas isoladamente.

Seria inviável trabalhar com tantas evocaçóes afinal a eficácia de uma representação social está assentada em seu consenso social ${ }^{22}$. Por isso filtramos as 146 categorias construídas anteriormente, estabelecendo como ponto de corte uma frequência igual ou superior a 5\% (103 questionários x 5\% = 5,2 , ou seja, cinco apariçóes) que é um percentual considerado relevante ${ }^{23}$.

\section{Resultados}

Na TABELA 2, apresentamos as 24 evocaçóes listadas pelo EVOC 2000 que tiveram uma frequência $(f x)$ maior ou igual a cinco, ordenando-as da mais para a menos frequente. Vale destacar que o número de 275 evocaçóes (que corresponde a soma de todas as evocaçóes apresentadas no referido quadro), equivalem a $60,4 \%$ do universo total de 455 evocaçóes que apareceram mediante a análise dos 103 testes devolvidos e considerados válidos.

TABELA 2 - Evocações assinaladas pelos professores de Educação Física da SEDU com frequência igual ou superior a cinco.

\begin{tabular}{cccccccc}
\hline Evocaçáo & $\boldsymbol{f x}$ & Evocaçáo & $\boldsymbol{f x}$ & Evocaçáo & $\boldsymbol{f x}$ & Evocação & $\boldsymbol{f x}$ \\
\hline aprender & 42 & inovação & 13 & informação & 7 & compromisso & 5 \\
qualificação & 26 & reciclagem & 12 & infraestrutura & 7 & continuidade & 5 \\
construção & 21 & oportunidade & 11 & motivação & 7 & crescimento & 5 \\
atualização & 19 & reflexão & 9 & caminhos & 6 & dedicaçáo & 5 \\
experiências & 19 & grupo de estudos & 8 & eventos & 6 & discussão & 5 \\
remuneração & 18 & qualidade & 8 & mudança & 6 & professor & 5 \\
\hline
\end{tabular}


Uma característica interessante do EVOC 2000 é a organização dos dados tratados, levantando hipotéticos elementos componentes do núcleo central. Para tanto, são levadas em consideração a frequência $(f x)$ e a Ordem Média de Evocação $(\mathrm{OME})^{\mathrm{g}}$, cabendo ao pesquisador definir os parâmetros mínimos que diferenciarão os componentes do núcleo central dos demais elementos da representação social.

Por meio do programa EVOC,

Os resultados são distribuídos em dois eixos ortogonais com as palavras de maior frequência e menor OME situadas no quadrante superior esquerdo, correspondente ao $\mathrm{NC}^{\mathrm{h}}$. As que se situam no quadrante superior direito constituem a 'periferia próxima' ao $\mathrm{NC}$; no quadrante inferior direito, que pode ser considerado a 'periferia propriamente dita', aparecem os elementos de menor frequência e evocação mais tardia; já o quadrante inferior esquerdo, por força da ambiguidade de suas coordenadas (menor frequência e evocaçáo mais próxima à dos elementos do NC), é de interpretação menos precisa ${ }^{24}$.

Baseando-nos em outras experiências de pesquisa com essa metodologia - e levando em conta a dispersão e o universo de associaçóes que a frase indutora "Quando ouço falar em formação continuada, penso em..." pôde provocar, principalmente após uma análise prévia dos dados lançados no EVOC conseguidos junto aos 103 sujeitos que devolveram e tiveram seus testes considerados válidos -, consideramos uma frequência maior ou igual a 15 e uma
OME menor que 2,5 como parâmetros aceitáveis para gerar diferenciaçóes visuais no eixo ortogonal ${ }^{i}$ que apresentaria os elementos componentes da representação de formação continuada segundo os professores de EF participantes da pesquisa.

A representação visual do eixo ortogonal construído na TABELA 3 corresponde a uma combinação dos parâmetros da frequência e da OME. O leitor pode observar que os dois quadrantes de cima (esquerda e direita) correspondem às evocações que foram mais citadas pelos colaboradores do estudo (maior frequência). Nos dois quadrantes imediatamente abaixo (esquerda e direita) estão as evocaçôes menos lembradas (menor frequência). Já os quadrantes da esquerda (de cima e de baixo) correspondem aos elementos com média aritmética baixa de ordem na qual as evocaçóes foram lembradas (menor OME), o que significa dizer que quanto menor for essa média o elemento é lembrado mais prontamente, isto é, aparece muito mais vezes nos primeiros dentre os cinco que podiam ser preenchidos pelos colaboradores do estudo. Os quadrantes da direita (de cima e de baixo), com valores maiores (maior OME), apresentam as evocaçóes que foram lembradas com menos prontidão.

É a partir da combinação desses dois parâmetros (frequência e OME) que construímos a discriminação visual apresentada na TABELA 3. Discriminação essa que torna possível realizar uma interpretação dos dados alcançados e, consequentemente, teorizar sobre os resultados obtidos.

TABELA 3 - Estrutura da representação social de formação continuada dos professores de Educação Física da SEDU a partir do termo indutor 'quando ouço falar em formação continuada, penso em...'

\begin{tabular}{|c|c|c|c|c|c|c|}
\hline Evocaçáo & $f x$ & $\mathrm{OME}<2,5$ & Evocaçáo & $f x$ & $\mathrm{OME}<2,5$ & \multirow{5}{*}{$\begin{array}{l}n \\
\stackrel{n}{11} \\
\hat{x}\end{array}$} \\
\hline \multirow{2}{*}{ aprender } & \multirow{2}{*}{42} & \multirow{2}{*}{2,214} & construção & 21 & 3,000 & \\
\hline & & & atualização & 19 & 2,526 & \\
\hline \multirow{2}{*}{ qualificação } & \multirow{2}{*}{26} & \multirow{2}{*}{1,846} & experiências & 19 & 3,263 & \\
\hline & & & remuneração & 18 & 3,611 & \\
\hline informação & 7 & 2,143 & inovaçăo & 13 & 2,692 & \multirow{12}{*}{ 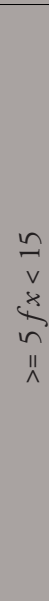 } \\
\hline caminhos & 6 & 1,833 & reciclagem & 12 & 2,533 & \\
\hline professor & 5 & 2,200 & oportunidade & 11 & 3,091 & \\
\hline compromisso & 5 & 2,357 & reflexão & 9 & 3,000 & \\
\hline continuidade & 5 & 2,375 & grupo de estudos & 8 & 3,375 & \\
\hline dedicação & 5 & 2,475 & qualidade & 8 & 2,875 & \\
\hline Núcleo Central & & & infraestrutura & 7 & 3,714 & \\
\hline Periferia próxima & & & motivação & 7 & 3,429 & \\
\hline \multirow{2}{*}{ Periferia propriamente dita } & & & eventos & 6 & 3,211 & \\
\hline & & & mudança & 6 & 3,000 & \\
\hline \multirow{2}{*}{$\begin{array}{l}\text { Evocaçōes de interpretação } \\
\text { menos precisa }\end{array}$} & & & crescimento & 5 & 3,250 & \\
\hline & & & discussão & 5 & 3,555 & \\
\hline
\end{tabular}


O critério quantitativo é capaz de indicar as cogniçóes de maior centralidade justamente por elas se apresentarem de uma maneira mais frequente ${ }^{13}$. Nesse sentido, é possível levantar uma hipótese para a provável composição do núcleo central e do sistema periférico para professores de EF da SEDU em relação a sua formação continuada, levando-se em conta a frequência $(f x)$ e a OME das evocaçóes assinaladas por eles (TABELA 3). Combinar esses dois parâmetros possibilita levantar os elementos "[...] que mais provavelmente pertencem ao núcleo central da representação, por seu caráter prototípico [...]"25 (p.117).

Compreendemos que "[...] graças ao seu valor simbólico e à sua polissemia, as cogniçõoes centrais ocupam um lugar privilegiado no discurso, sendo evocadas mais frequentemente que as demais [...]"14 (p.23)" e por meio da construção do eixo ortogonal, é possível verificar termo(s) mais saliente(s).

No que tange a análise dos elementos apresentados no eixo ortogonal, apresentado na TABELA 3 , podemos perceber que as evocaçóes "aprender" e "qualificação" compóem o núcleo central da representação social de formação continuada dos professores de EF da SEDU porque possuem uma OME mais baixa e uma frequência mais alta. Ao que parece a aprendizagem corresponde a um fator importante na FC continuada para os professores juntamente com a qualificação.

Nenhuma novidade até aqui, pois parece até meio óbvio que quando um professor decida participar de um programa de FC ele busque aprender novos conteúdos, métodos e teorias, com vistas a uma melhor qualificação. O que vimos com curiosidade foi a evocação "qualificação" apresentar uma OME menor do que "aprender" (1,846 contra 2,214, respectivamente), o que significa dizer que qualificação foi mais prontamente lembrada do que aprendizagem entre os sujeitos participantes do estudo, ainda que essa última tenha apresentado uma frequência maior do que a primeira ( 42 contra 26 contra, respectivamente).

Os elementos que compóem a periferia próxima parecem dar sustentabilidade ao núcleo central. Pois entendemos que, para os sujeitos participantes da pesquisa, "construção" e "experiências" possuem estreita relação com "aprender”, enquanto que "atualização" e "remuneração" parecem estar mais vinculadas a ideia de "qualificação".

Os elementos que compóem a periferia propriamente dita nos trazem algumas pistas que talvez possam indicar como os professores de EF da SEDU gostariam que a formação continuada fosse construída ("grupo de estudos", "eventos" e "reflexão"), os motivos que eles teriam para participar da mesma ("inovação", "reciclagem", "motivação", "mudança”, "crescimento" e "discussão”), bem como algumas características que eles julgam pertinentes na construção de programas de formação continuada ("oportunidade", "qualidade" e "infraestrutura").

São fortes, portanto, os indícios que apontam que as evocações "aprender" e "qualificação" compóem o núcleo central das representaçóes sociais de FC dos professores de EF da SEDU. Contudo, apenas a construção do eixo ortogonal feita pelo EVOC (TABELA 3) e a interpretação que construímos não seria suficiente para confirmar nossa hipótese. Era necessário que os dados alcançados passassem pelo crivo do Poder de Associação de Uma Evocação.

Na TABELA 4 apresentamos a matriz que criamos para melhor visualizar o poder de associação existente entre as evocaçóes. Estabelecemos como um critério de associação o valor de $10 \%$ entre as evocaçôes, levando em conta o elemento que foi mais vezes lembrado ("aprender", $f \boldsymbol{x}=42$ ), para determinar um índice que nos possibilitasse discriminar visualmente essa relação $(42 \times 10 \%=4,2)$. Consideramos então que duas evocaçóes possuiriam um relevante Poder de Associação quando fossem citadas juntas, no mesmo teste, por quatro ou mais professores de EF diferentes.

Levando-se em conta a dispersão de valores apresentados na matriz e o mais alto valor de associação ("aprender"-"qualificação" = 11 associaçóes) arbitramos que $50 \%$ seria o limite para classificar se duas evocaçóes possuíam um maior ou um menor poder de associação entre si $(11 \times 50 \%=5,5$, ou seja, aproximadamente seis apariçóes conjuntas).

Sendo assim, destacamos as evocaçóes que estavam ligadas entre si com maior poder mediante a utilização de numeração na cor branca sobre um fundo preto (mais que seis apariçóes conjuntas) e as evocaçóes que possuem um menor poder de associação (maior ou igual a quatro e menor ou igual a seis citaçôes) com os números em preto e em negrito.

Vale destacar que a TABELA 4 corresponde a uma matriz que tem por objetivo favorecer a visualização do poder de associação que uma evocação mantém com as outras. Sendo assim, para buscar quantas vezes uma determinada evocação foi citada junta com outra por sujeitos diferentes basta buscá-la em uma linha e fazer a interseção com a evocação disposta na coluna (por exemplo: "aprender" e "atualização" apareceram em um mesmo questionário citadas por 10 sujeitos diferentes). Também por isso que na interseção de uma evocação da linha com ela mesma na coluna sempre dá zero como resultado (por exemplo: 
“inovação" e "inovação"), porque cada evocação é citada apenas uma vez por cada sujeito. Nos outros casos nos quais aparece zero na interseção significa dizer que a evocação não foi citada junta com aquela outra em nenhum dos mais de cem questionários analisados (por exemplo: "dedicação" e "aprender").

TABELA 4 - Matriz do poder deassociação das evocações assinaladas pelos professores deEducação Física da SEDU.

\begin{tabular}{|c|c|c|c|c|c|c|c|c|c|c|c|c|c|c|c|c|c|c|c|c|c|c|c|c|}
\hline Evocação & 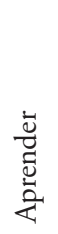 & 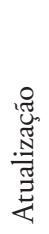 & $\frac{\mathscr{\varrho}}{\stackrel{\Xi}{\Xi}}$ & 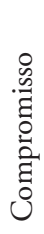 & 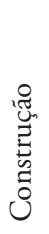 & 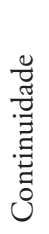 & 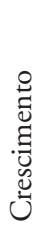 & 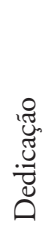 & 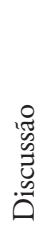 & 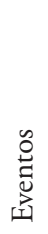 & 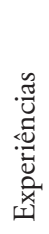 & 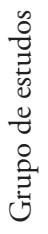 & 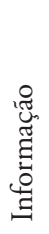 & 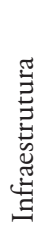 & 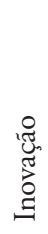 & 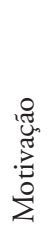 & 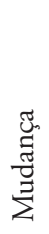 & 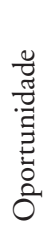 & 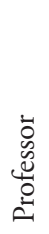 & 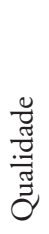 & 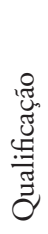 & 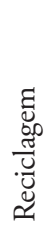 & 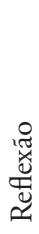 & 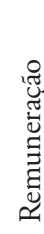 \\
\hline Aprender & 0 & 10 & 4 & 3 & 9 & 2 & 7 & 0 & 0 & 1 & 10 & 4 & 3 & 2 & 3 & 2 & 4 & 5 & 2 & 2 & 11 & 7 & 3 & 0 \\
\hline Caminhos & 4 & 0 & 0 & 0 & 2 & 0 & 1 & 1 & 0 & 0 & 1 & 0 & 0 & 0 & 1 & 0 & 0 & 2 & 0 & 1 & 0 & 0 & 2 & 0 \\
\hline Compromisso & 3 & 2 & 0 & 0 & 4 & 0 & 1 & 4 & 0 & 0 & 1 & 0 & 1 & 0 & 0 & 1 & 0 & 0 & 0 & 0 & 1 & 0 & 1 & \\
\hline Construção & 9 & 3 & 2 & 4 & 0 & 1 & 3 & 0 & 0 & 2 & 3 & 1 & 0 & 4 & 3 & 4 & 2 & 3 & 1 & 1 & 4 & 1 & 3 & \\
\hline Discussão & 0 & 0 & 0 & 0 & 0 & 0 & 1 & 0 & 0 & 0 & 4 & 4 & 0 & 0 & 1 & 0 & 1 & 0 & 0 & 0 & 0 & 0 & 1 & \\
\hline Eventos & 1 & 2 & 0 & 0 & 2 & 0 & 1 & 0 & 0 & 0 & 3 & 1 & 0 & 0 & 0 & 1 & 0 & 0 & 0 & 0 & 4 & 1 & 0 & \\
\hline Experiências & 10 & 3 & 1 & 1 & 3 & 0 & 2 & 0 & 4 & 3 & 0 & 2 & 3 & 0 & 3 & 2 & 1 & 2 & 0 & 2 & 2 & 2 & 4 & \\
\hline $\begin{array}{l}\text { Grupo } \\
\text { de estudos }\end{array}$ & 4 & 0 & 0 & 0 & 1 & 0 & 1 & 0 & 4 & 1 & 2 & 0 & 1 & 2 & 1 & 0 & 0 & 0 & 0 & 0 & 0 & 2 & 1 & \\
\hline Informação & 3 & 2 & 0 & 1 & 0 & 0 & 0 & 0 & 0 & 0 & 3 & 1 & 0 & 0 & 1 & 1 & 1 & 0 & 0 & 1 & 4 & 0 & 0 & \\
\hline Infraestrutura & 2 & 0 & 0 & 0 & 4 & 1 & 1 & 0 & 0 & 0 & 0 & 2 & 0 & 0 & 2 & 0 & 0 & 1 & 2 & 0 & 1 & 0 & 0 & \\
\hline Qualidade & 2 & 2 & 1 & 0 & 1 & 0 & 3 & 0 & 0 & 0 & 2 & 0 & 1 & 0 & 0 & 1 & 0 & 0 & 0 & 0 & 1 & 1 & 0 & \\
\hline Qualificação & 11 & 4 & 0 & 1 & 4 & 5 & 1 & 0 & 0 & 4 & 2 & 0 & 4 & 1 & 4 & 0 & 3 & 1 & 0 & 1 & 0 & 1 & 0 & \\
\hline Reciclagem & 7 & 3 & 0 & 0 & 1 & 0 & 2 & 0 & 0 & 1 & 2 & 2 & 0 & 0 & 2 & 2 & 1 & 0 & 0 & 1 & 1 & 0 & 0 & 0 \\
\hline Reflexão & 3 & 1 & 2 & 1 & 3 & 0 & 0 & 0 & 1 & 0 & 4 & 1 & 0 & 0 & 2 & 1 & 1 & 1 & 0 & 0 & 0 & 0 & 0 & 0 \\
\hline Remuneração & 0 & 0 & 0 & 0 & 0 & 0 & 2 & 1 & 0 & 1 & 1 & 0 & 0 & 0 & 0 & 2 & 0 & 2 & 1 & 0 & 4 & 0 & 0 & 0 \\
\hline
\end{tabular}

Novamente comprovamos, agora pelo critério estabelecido pelo poder de associação, que é plausível considerar "aprender" e "qualificaçáo" como componentes do núcleo central. Afinal, o primeiro está vinculado com 10 elementos (seis de maneira mais forte e quatro de maneira menos forte), enquanto o segundo se liga com oito elementos (um de maneira mais forte e outros sete de maneira menos forte). Sem falar que a ligaçáo entre essas duas evocaçóes é a mais forte de todas se comparada com todos os outros elementos que possuem uma ligação forte. 


\section{Discussão}

\section{Análise da representação social de formação continuada dos professores de Educação Física da SEDU}

De maneira a favorecer uma visualização da ligação numérica estabelecida entre as evocações retomamos os dados tratados que foram apresentados na TABELA 4 e construímos um esquema que pudesse fazer uma hipotética representação gráfica da estruturação da representação social de formação continuada dos professores de EF da SEDU (FIGURA 1). Para tanto, utilizamos os seguintes critérios: eliminamos as evocaçóes que foram citadas juntas por menos de quatro professores ("professor" e "qualidade"); traçamos uma linha mais espessa entre os elementos que apresentaram um maior poder de ligação entre si (mais do que seis apariçóes conjuntas); e traçamos uma linha mais fina unindo os elementos com menor poder de ligação (maior ou igual a quatro e menor ou igual a seis). Também destacamos com quadros pretos os elementos que compóem o núcleo central e em cinza aquelas evocaçóes que formam a periferia propriamente dita.

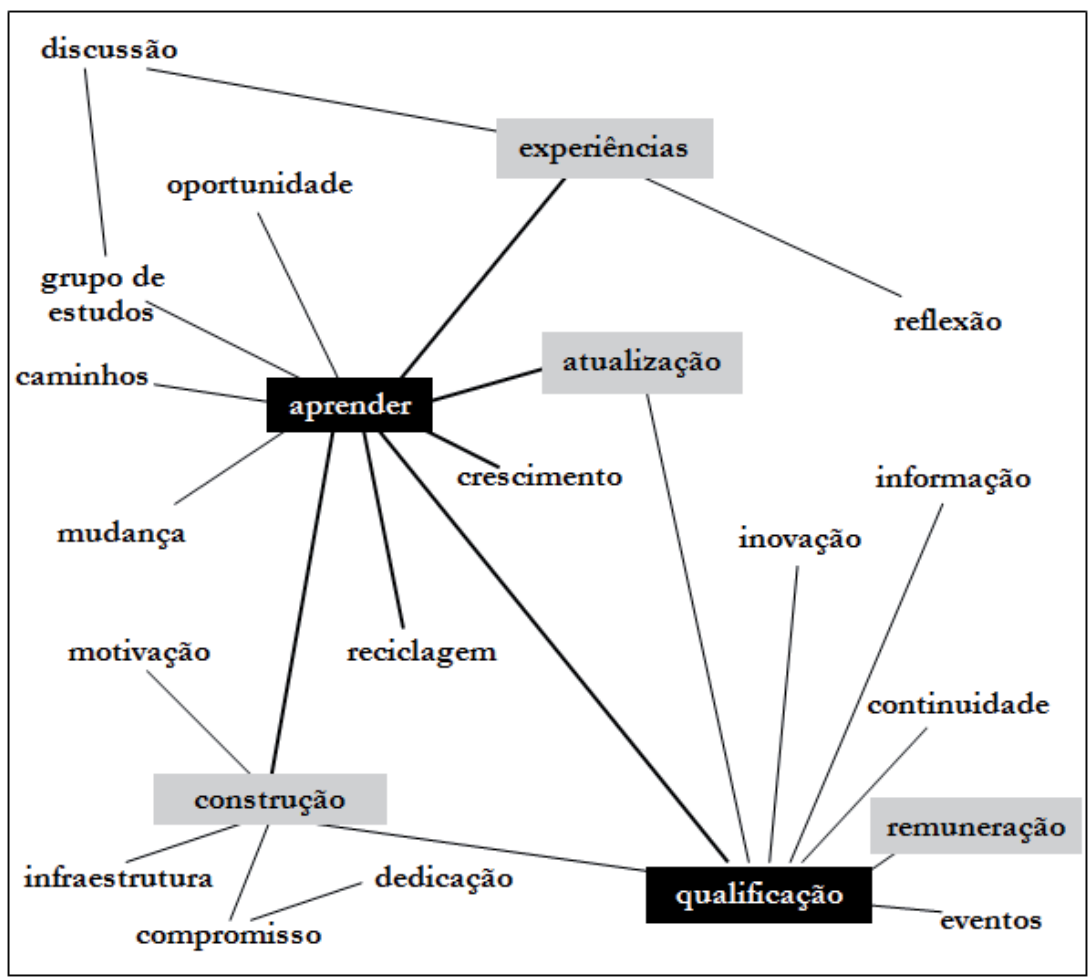

FIGURA 1 - Representação gráfica da estruturação da representação social de formação continuada dos professores.

Podemos perceber que em torno do componente do núcleo central "aprender", verifica-se a presença de algumas evocações soltas, isto é, sem nenhum tipo de ligação com outra/s, sem formar cadeias ou ciclos, o que parece indicar não haver um consenso social em torno delas, como se elas fossem usadas comumente como clichês. São elas: "mudança”, "caminhos", "oportunidade", "crescimento" e "reciclagem" que parecem não ter um significado mais forte para aqueles sujeitos. O mesmo ocorre com "qualificação", que também, compondo o núcleo central, possui as evocações "inovação", "informação", "continuidade" "e "eventos" ligadas apenas a ela.

Apesar da evocação "remuneração" não formar nenhuma cadeia ou ciclo abrimos exceção por considerá-la um elemento que dá sustentação para a evocação "qualificação", pois ela foi citada 18 vezes, compondo assim a periferia próxima da representação social (rever TABELA 2). Por esse motivo "remuneração” foi a única evocação que mantivemos após a limpeza que realizamos para facilitar a visualização das cadeias formadas (FIGURA 2). 


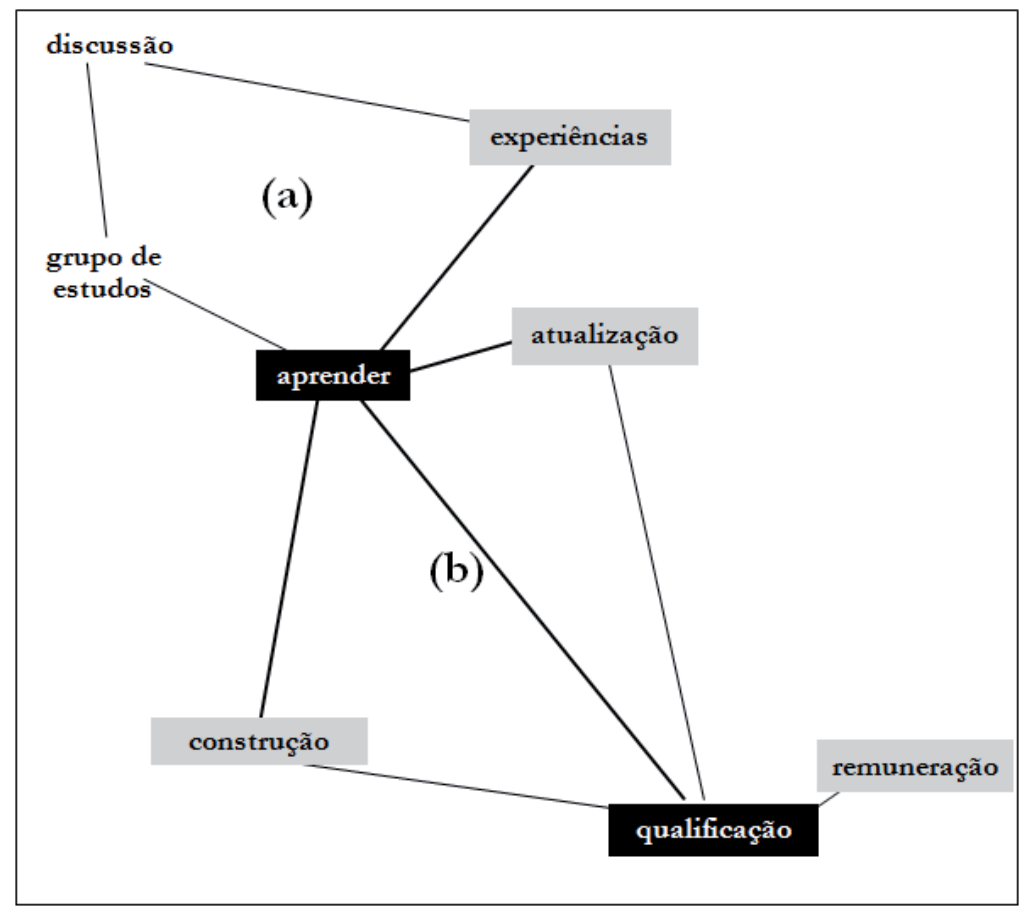

FIGURA 2 - Representação gráfica dos polígonos formados em torno da evocação "aprender”.

Dá para notar na FIGURA 2 que se formam alguns polígonos em torno das evocaçóes filtradas. Contudo apenas a formação dessa figura não é suficiente sendo necessário "[...] para completar a análise, construir uma argumentação sobre como esses diferentes componentes se relacionam ao contexto e às atitudes, aos valores, às referências dos sujeitos"14 (p.25).

Observando atentamente os quadriláteros (a) e (b) é possível perceber que mesmo contendo a evocação central "aprender" como vértice comum, a estruturação da representação social dos professores de EF da SEDU parece estar situada em dois sentidos distintos e é a evocação central "qualificação" que parece conferir essa especificidade.

Afinal percebemos que se, por um lado, os professores de EF tem uma representação social de FC que corresponde a um processo de aprendizagem coletivo no qual eles entendem que a troca de experiências, a discussão e a participação em açóes coletivas como em grupo de estudos, por exemplo, por outro, eles parecem concentrar seus esforços na construção da própria qualificação, na busca por aprendizagens que possam mantê-los atualizados, com o objetivo não apenas de alcançar melhores salários, que indica-nos uma empreitada individual, mas também para manterem-se empregados. Seria o indício de que existem sentidos opostos dentro da representaçáo social de FC dos professores de EF da SEDU?
Com base nas análises que fizemos é possível supor, por hora, que os professores de EF da SEDU estejam em processo de objetivação. Objetivar nas TRS significa, de uma maneira geral, transformar em objeto aquilo que é representável, mas nesse caso em especial significa que a representação social de FC está ganhando um novo significado.

Levantamos a hipótese de que há um processo de deslocamento do núcleo central da representação social de FC em curso porque, se em outros estudos realizados com professores da Educação Básica de outras redes de ensino a formação continuada é representada como "troca de experiências"26, "crescimento, mudança e participação" ${ }^{27}$, na investigação que realizamos a qualificação começa a ocupar um lugar muito importante na representaçáo social de formação continuada dos docentes da SEDU.

Acreditamos que a política de contrataçấo de professores adotada pela SEDU - que mantém quase $3 / 4$ do total de professores de Educação Física da rede pública estadual com contratos de apenas 11 meses por ano, sem qualquer tipo de garantia de uma nova contrataçáo no ano letivo subsequente - vem contribuindo, em grande medida, para que a representação de formação continuada desses professores venha se transformando.

Dessa maneira os docentes em questáo estariam assumindo para si uma prerrogativa do mundo empresarial que os administradores insistem em transformar em atributo individual: a busca por qualificação. 
Ainda no campo da hipótese, acreditamos que diante de um contexto social no qual a competição, o individualismo e a busca por emprego são marcas irrefutáveis, o trabalhador, que deseja se (re)posicionar (melhor) diante do mercado, assume individualmente tal necessidade.

Não é de estranhar que esse tipo de mudança possa estar acontecendo, uma vez que os professores contratados - que são maioria esmagadora no quadro de vagas da SEDU ( $77,3 \%$ ou 588 , do total de 761 de docentes de EF no ano letivo de 2008) - precisam participar de cursos de FC se quiserem ficar bem classificados nos processos seletivos simplificados que são abertos ao final de cada ano, pois a SEDU não possui uma política de formação continuada sistemática destinada aos seus professores, sejam eles efetivos ou contratados.

É digno de destaque que os professores efetivos da SEDU só obtêm crescimento na Rede Estadual (progressão na carreira e aumento de rendimentos) se participarem de cursos de formação continuada na modalidade de pós-graduação ("lato senso" e "stricto senso"). Cursos de formação continuada de qualquer outro tipo não acrescentam em nada para estes docentes, uma vez que não há um plano de cargos e salários na Rede.

Diante dos dados analisados é necessário afirmar que será impossível pensar em promover qualquer melhoria no processo de FC dos professores de EF da SEDU sem realizar um concurso público imediato para diminuir a vergonhosa estatística que aponta que mais de $3 / 4$ dos professores de $\mathrm{EF}$ dessa rede são contratados por tempo determinado. Outra questão que precisa ser resolvida é a ausência de um plano de cargos e salários para os professores da SEDU.É de fundamental importância que o docente que trabalha Rede Estadual saiba em que nível ele está, qual o nível a que ele pode chegar e o que precisa ser feito em relação a cursos e outros tipos de estudos para alcançá-lo.

Após resolver essas duas questôes essenciais é preciso que a SEDU sistematize um trabalho de diálogo de longo prazo entre os professores de suas escolas e os pesquisadores da universidade, de maneira a criar uma via de mão dupla que promova a troca entre o que vem sendo construído de mais recente em relação à produção de conhecimento na academia e o que vem sendo produzido de práticas e saberes pelos professores, bem como para atender as demandas desses docentes, que são os indivíduos que materializam com os alunos das escolas da Educação Básica a EF discutida dentro das universidades.

A partir dos resultados e das sugestóes que apresentamos, entendemos ser necessária a realização de novos e mais aprofundados estudos sobre as representaçóes sociais de FC com outros professores de maneira a verificar se a hipótese levantada é confirmada em contextos distintos e com sujeitos diferentes. Para tanto, sugerimos que seja levado em consideração não apenas o processo de construção coletiva deste conceito na mente dos docentes, mas também a história de vida dos sujeitos participantes dos estudos, a produção intelectual dos pesquisadores universitários, as notícias veiculadas pelos meios de comunicação, o ordenamento legal da educação no País e a opiniáo e a açáo dos movimentos sociais organizados que representam e defendem os docentes, como os sindicatos e as associaçóes de professores.

\section{Notas}

a. Consideramos formaçôes continuadas oficiais os programas conduzidos pelos órgãos estatais municipais e estaduais e pelo governo federal.

b. A expressão "representaçôes sociais" pode ser usada para descrever tanto a teoria quanto o objeto estudado. Como forma de diferenciaçáo do uso da expressáo neste trabalho, toda vez que nos referirmos à tal teoria, usaremos a sigla TRS e, quando estiver tratando do fenômeno ou do objeto, usaremos representaçóes sociais com iniciais minúsculas.

c. Quando a pesquisa apresentada foi realizada não havia um comitê de ética instituído no Programa de Pós-Graduação em Educação Física da Universidade Federal do Espírito Santo. No entanto, foram criadas condiçóes para garantia do anonimato dos sujeitos que participaram deste estudo, bem como foi realizada a assinatura de um Termo de Consentimento Livre e Esclarecido com os mesmos. Esse documento: informava sobre os objetivos e métodos que seriam empregados na investigaçáo; garantia a cada informante o direito de obter informaçóes acerca de como foram tratados os dados obtidos sobre ele; permitia que cada sujeito optasse por não mais participar do estudo caso se sentisse invadido ou se julgasse necessário por qualquer outro motivo.

d. É importante frisar que a teoria das Representaçóes Sociais trabalha com a correlação existente entre o senso comum e os conhecimentos científicos sem pretender, em hipótese alguma, diluir as especificidades que diferenciam essas duas modalidades do conhecimento humano entre si. 
e. A abordagem processual valoriza a articulação entre a dimensão social e cultural na formação das construções mentais coletivas, preocupando-se assim com a gênese das representaçóes sociais, levando em conta tanto a historicidade dos sujeitos envolvidos quanto o contexto de produçáo das representaçóes sociais. A abordagem societal busca articular explicaçôes individuais com explicaçóes sociais, lembrando que as decisôes individuais tomadas são orientadas pelas interaçôes sociais, tratando, dessa maneira, da relação existente entre os processos sociais e cognitivos. A abordagem estrutural trata da organização interna e da dimensão cognitiva de uma representaçáo social priorizando estudar como ela se objetiva.

f. Os professores efetivos são aqueles que, mediante concurso público, se tornaram parte integrante do quadro permanente de funcionários públicos do Estado, enquanto educadores em designação temporária (contratados) são aqueles que dão aula mediante contrato (durante um período de tempo delimitado) que pode ou náo ser renovado ao final de seu prazo.

g. A OME corresponde à média aritmética da posição em que cada evocação foi citada pelos colaboradores do estudo. Ter uma OME menor significa que a evocação foi lembrada mais prontamente do que as outras com uma OME maior.

h. NC é a abreviatura usada para núcleo central ${ }^{8}$.

i. Escolhemos uma frequência maior ou igual a 15 porque apenas seis (25\%) das 24 evocações possuem uma frequência maior ou igual a cinco. A OME definida foi 2,5 por esse valor corresponder à metade do úmero de evocaçóes que os sujeitos participantes do estudo podiam assinalar no Teste de Livre Evocação de Palavras.

\begin{abstract}
The social representation of continuing education for Physical Education teachers of the State of the Espirito Santo

The main purpose of this text is to present the initial results of an investigation that aimed at understanding the social representation of the Physical Education teachers belonging to State School System in the State of Espírito Santo regarding its continuing formation. To do so, the great theory of Social Representations was chosen, especially due to the importance it attributes to the common sense, which is considered one of the central notions for the concept of social representation. Opting for the Structural Approach, which corresponds to one of the three chains that compose such theory, it raises hypothesis about the social representation of continuing formation, dealing with its internal organization and cognitive dimension. It indicated for the occurrence of a current phenomenon that has been displacing the central nucleus of social representation of the learning continuing formation to the qualification, making the search for qualification regarding continuing formation as an individual attribute with sole and exclusive Teacher's responsibility.
\end{abstract}

KeY WoRds: Social representations; Central core; Structural approach; Common sense.

\title{
Referências
}

1. Martins AR. Na formação continuada não basta só tapar os buracos. Rev. Nova Esc. 2008;216:54-7.

2. Universidade Estadual de Campinas. Anuário estatístico base 2010. Campinas: UNICAMP; 2011. Disponível em: http://www.aeplan.unicamp.br/anuario_estatistico_2011/index_arquivos/anuario2011.pd.

3. Oliveira EM. Educação a distância; a velha e a nova escola. Pucviva. 2005;24:23-42.

4. Espírito Santos (Estado). Secretaria de Educação. Relatório de execução das ações de formação do magistério. Vitória: SEDU; 2010. Disponível em: http://www.educacao.es.gov.br/download/PRONTO_GEFOR_2011relizacoes2010.pdf.

5. MEC investirá dinheiro extra em formação de professores. R7 Notícias. 30 out. 2009: Educação. [citado 21 jan. 2010]. Disponível em: http://noticias.r7.com/vestibular-e-concursos/noticias/mec-investira-dinheiro-extra-em-formacao-de-professores-20091030.html.

6. Professores da educação básica terão bolsas de mestrado. Folha de S.Paulo. 21 mar. 2011: Educação. [citado 30 mai. 2011]. Disponível em: http://www1.folha.uol.com.br/saber/891789-professores-da-educacao-basica-terao-bolsas-de-mestrado.shtml. 
7. Loureiro W, Caparróz FE. Formação continuada em descontinuidade: política de mandato ao invés de política de Estado. Rev Meta. 2011;7:109-24.

8. Alves-Mazzotti AJ. Representaçôes da identidade docente: uma contribuição para a formulação de políticas. Ensaio: Aval Pol Pública Educ. 2007;57:579-94.

9. Minayo MCS. O conceito de representaçôes sociais dentro da sociologia clássica. In: Guareschi P, Jovchelovitch S, organizadores. Textos em representaçóes sociais. 8a ed. Petrópolis: Vozes; 2003. p.89-111.

10. Wachelke JFR, Camargo BV. Representações sociais, representações individuais e comportamento. Rev Interam Psicol. 2007; 41:379-90.

11. Alves-Mazzotti AJ. Representaçôes sociais: aspectos teóricos e aplicaçôes à educação. Múlt Leituras. 2008;1:18-43.

12. Nascimento-Schulze CM, Camargo BV. Psicologia social, representaçôes sociais e métodos. Temas Psicol. 2000;8:287-99.

13. Campos PHF. Abordagem estrutural e o estudo das relações entre práticas e representaçôes sociais. In: Campos PHF, Loureiro MCS, organizadores. Representaçóes sociais e práticas educativas. Goiânia: Editora da Universidade Católica de Goiás; 2003. p.21-36.

14. Alves-Mazzotti AJ. A abordagem estrutural das representaçóes sociais. Psicol Educ. 2002;14/15:17-37.

15. Saraiva ACLC. Representaçóes sociais da aprendizagem docente por professores universitários. 30a Reunião Anual da ANPED; 7-10 out. 2007; Caxambu, BR. Caxambu: ANPED; 2007. [citado 15 jun. 2009]. Disponível em: http:// www.anped.org.br/reunioes/30ra/trabalhos/GT08-3683--Int.pdf.

16. Mazzotti AJ. Reformas internacionais da educação e formação de professores. Rev Bras Estud Pedagog. 2006;217:349-59.

17. Nóbrega SM, Coutinho MPL. O teste de associação livre de palavras. In: Coutinho MPL, et al., organizadores. Representações sociais: abordagem interdisciplinar. João Pessoa: EdUFPB; 2003. p.67-77.

18. Teixeira MCTV, Baláo SMS, Settembre FM. Saliência de conteúdos de representação social sobre o envelhecimento: análise comparativa entre duas técnicas associativas. Rev Enferm. 2008;16:518-24.

19. Albuquerque ER, Machado LB. "Sem amor não se consegue desenvolver um bom trabalho": análise das representaçôes sociais de professoras sobre inclusão escolar. Rev Educ Espec. 2009;33:73-84.

20. Almeida AMO. A pesquisa em representaçóes sociais: proposiçóes teórico-metodológicas. In: Santos MFS, Almeida LM, organizadores. Diálogos com a teoria das representaçôes sociais. Recife: Editora Universitária da UFPE; 2005. p.117-60.

21. Vergès P. Approche du noyau central: propriétés quantitatives et struturales. In: Guimelli C. editor. Structures et transformations des représentations sociales. Lausanne: Délachaux et Niestlé; 1994. p.233-53.

22. Moscovici S. Representação social da psicanálise. Rio de Janeiro: Zahar; 1978.

23. Wachelke JFR. Índice de centralidade de representaçóes sociais a partir de evocaçóes (INCEV): exemplo de aplicação no estudo da representação social sobre envelhecimento. Psicol Reflex Crít. 2009;22:102-10.

24. Flament C. Aspects périphériques des représentations sociales. In: Guimelli C, editor. Structures et transfo-rmations des répresentations sociales. Lausanne: Délachaux et Niestlé; 1994. p. 85-118.

25. Sá CP. Núcleo central das representaçôes sociais. 2a ed. Petrópolis: Vozes; 2002.

26. Lehmkuhl I, Rafaeli KSC, Silva NMA. Representaçóes sociais dos professores das séries iniciais: saberes sobre a própria formação. 7o Congresso Nacional de Educação; 5-8 nov. 2007; Curitiba, BR. Curitiba: PUC-PR; 2007. [citado 1 mar. 2014]. Disponível em: http://www.pucpr.br/eventos/educere/educere2007/anaisEvento/arquivos/PA-277-04.pdf.

27. Machado LB. Representações sociais, educação e formação docente: tendências e pesquisas na IV Jornada Internacional. Educ. em Foco. 2008:1-10. [citado 1 mar. 2014]. Disponível em: http://www.fundaj.gov.br/geral/educacao_foco/ representantessociaislaedamachado.pdf.

ENDEREÇO

Walk Loureiro

R. Loren Reno, 92

29018-120 - Vitória - ES - BRASIL e-mail: walk.1@uol.com.br
Recebido para publicação: 16/04/2013

1a. revisão: $13 / 03 / 2014$

2a. revisão: $25 / 01 / 2015$

Aceito: 04/03/2015 